\title{
Landscape characteristics in Tartu City Parks: user influences through design
}

\author{
K. Maikov \\ Estonian University of Life Sciences, Estonia
}

\begin{abstract}
The greeneries on city maps are usually covered in large green areas, but that does not reveal much. The important factors to be considered in relation to greenery are, for example, distance, visiting frequency and accessibility. In the current study, all of the 92 urban green spaces (UGS) of the Estonian city Tartu are explored from a health perspective along with the landscape characteristic. The main purpose is to prove statistically how the parks are influenced by landscape elements using Searles' theory (1960) and main aspects. The CAD maps are represented by topics and graphs illustrating the situation in Tartu. Green room elements are found using Searles' theory: water/stone, plants, animals and other people. The main aspects are trees/plants, peace/openness, senses and visual elements. The health-promoting landscape characteristics are serene, wild, rich in species, spacious, prospective, refuge, festive and cultural. The parks were assessed by an expert group in the summer of 2011. The work is unique, thanks to the fact that the information is gained from greenery - albeit can be found and felt (information from the surrounding environment and direct reflections of consciousness through the senses). Green spaces characterised by serenity have a statistical correlation (Pearson) with peace/openness $(r=0.459$, $\mathrm{p}<0.01)$ and with senses $(\mathrm{r}=0.486, \mathrm{p}<0.01)$. Wilderness characteristic and trees/plants are also in correlation $(\mathrm{r}=0.423, \mathrm{p}<0.01)$. According to literature, design is the least influential aspect in landscape. The author can statistically prove that design is strongly correlated with user influence through the senses $(\mathrm{r}=0.501, \mathrm{p}<0.01)$, and not visual aspects, as was expected in the case of Tartu. Landscape characteristics are the attributes that landscape architects can use for design work.
\end{abstract}

Keywords: PSD (Perceived Sensory Dimensions), CAD maps. 


\section{Introduction}

\subsection{Tartu}

Tartu received its first public park Toomemägi from Emperor Paul I of Russia thanks to the University of Tartu in 1799. The activities in the park were designed by architect J. W. Krause [1]. Tartu is well equipped with greeneries. Tartu is a healthy and health-promoting city [2] with 390.3 ha $(10.1 \%)$ of parks and greeneries. All the residents are living within a $300 \mathrm{~m}$ zone from a public space $(79 \%, 79,385$ people) [3]. More than $50 \%$ of the space in the Ihaste neighbourhood is under greenery. All 92 greeneries were evaluated. They were located as follows: 24 UGS in the city centre, 11 in Tähtvere, 8 in Ihaste and Annelinn, 7 in Raadi-Kruusamäe, Karlova and Ülejõe, 6 in the Maarjamõisa neighbourhood, 4 in Tammelinn, 3 in Jaamamõisa, 2 in Ropka and the Ropka industrial district and 1 in Veeriku, Vaksali and Supilinn. There were none in Ränilinn.

\subsection{Landscape characteristics}

Landscape characteristics [4]/PSD [5] are a landscaping concept entailing different space properties [4], which are necessary in order to make a landscape a healing one [6]. In a healing environment of landscape characteristics [5], each space property manifests itself through the senses such as sight, hearing, movements $[4,6,7]$.

\subsection{Tyson}

Tyson [8] has found that most users $-69 \%$ - are influenced by trees/plants (trees, flowers, colours, seasonality), 50\% are influenced by psychological aspects (peace/openness), $26 \%$ by senses (animals, wind, fresh air), and $17 \%$ by visual values (design, views, elements). The greenery in Tartu looks modest.

\subsection{Public health}

Public health has always been an important objective in city planning. Evidence about the positive impact that natural environments have on people is based on evolution theories. According to some authors, features such as vegetation, bubbling water, openness, savannah-like spaces, birds and safety impart a sense of belonging to people [9]. Evidence gathered from historical research and surveys indicates that most city residents attach considerable importance to urban forests and parks, and that views of trees, grass and open spaces provided by such settings are considered to be very important environmental amenities $[10,11]$. At a general level, one consistent finding has been that the presence of vegetation, especially trees, has a positive impact on preference [12]. It appears that many, if not most urbanites derive greater benefit from viewing natural scenery and passively enjoying other natural amenities in parks than from active 
recreation [12]. In total, an estimated average of 220 hours per person is spent in urban open green spaces every year [13].

\subsection{Some senses}

Some senses can be defined as distance senses (vision, hearing and, to some extent, smell), while other senses are nearness senses. The brain interprets information from all our senses together with memories of earlier episodes, which gives us a full experience and understanding of our environment [14].

\subsection{Searles}

Searles [15] also pointed out that signals from nature act as a catalyst, sparking creative processes that are important for restoration. Our relations to other people are the most complex, while the simplest ones happen between inanimate objects, e.g. stones, and us. Plants and animals remain somewhere in between.

\subsection{Design issues}

Greeneries have been well-known throughout history and dendrology. The designs have simply incorporated trees and used only a few accessories in different areas that are small or have no space. Trees are used as accents, there are views to lawn areas etc.

\section{Methods}

\subsection{Evaluation of parks}

The group visited all parks together during four days, spending approximately 15 minutes in each park or UGS. While in the park, the group discussed and agreed upon an evaluation. All the theories were read out loud in every single park and, the park/UGS was evaluated according to the scale (impression of the entire park), and the result was entered into prepared tables. Public spaces were valued under the topic: green living city nature.

\subsection{Expert group}

The expert group was hired by the main author. The members had graduated with a landscape architect degree, had followed an environmental psychology course and were familiar with the theories and methods used in the study thanks to their lectures and exercises. A three-person expert group evaluated the parks in the summer of 2011.

\subsection{Creation of CAD MAPS}

Various topic maps were created using layers named after topics. The assessment scale was transformed into three colours ( 0 - was not used on CAD maps): light- 
toned - low presence (1); mid-toned - medium presence (2); dark-toned - strong presence (3).

\subsection{Statistical analysis}

The data were entered in an Excel table and analysed in SPSS (version 2.0). Information about each park was coded. The main codes followed the assessment scale (0-3). The correlation matrix in SPSS was made using the Pearson linear correlation, following a probability level for finding connections. In this paper, strong connections start from the value 0.4. For statistical significance, the following was used $-\mathrm{p}<0.01$. Very important connections $(99 \%$ believable) are marked with $* *$ in the tables.

\subsection{Theories: landscape characteristics}

In this study, the author used the original terminology related to the theory.

Serene - peace, silence and caring. Sounds of wind, water, birds and insects. No rubbish, no weeds, no disturbing people [4]. The main aim is to hear sounds, and the main senses are hearing, thinking and feeling the temperature. In such a landscape one can find pure city nature that one expects to be comfortable; something that all parks possess.

Wild - fascination with the wild. Plants seem to be self-sown. Lichen and moss grow on rocks, there are old paths $[4,6]$. The park is described as dynamic and having inner vitality contained in untouched nature, where plants are still growing and maintaining themselves. The space offers users the opportunity to feel the power of nature and its dominance over humans. The atmosphere makes people feel safe and imparts a feeling of togetherness [16]. Untouched natural environments are assessed according to criteria concerning public spaces.

Rich in species - a space that offers a variety of species or animals and plants [4]. Characteristics that offer experiences with different forms of life and diversity (birds, animals, butterflies, flowers). People are very keen to gain experiences through cognition [16]. The space is expected to be rich in species and abundant in greenery.

Space - a space that offers a relaxing feeling of "entering another world", a coherent whole, such as a beech forest [4]. The feeling is based on openness and freedom, and the different parts of the space are felt as a whole [16]. Typically, there are collections of tree trunks in well-maintained areas.

Prospect - a green, open space that provides vistas and invites the user to stay [4]. The space is characterised by openness, crudeness through panoramic views, and lots of room for activities that need it (ballgames, picnics, social events) [16].

Refuge - an enclosed, safe and secluded place, where you can relax, be yourself and also experiment and play [4]. The user can see others engaging in activity, many trees, bushes, and higher plants [16]. There are little intimate places inside larger areas.

Festive - a meeting place for festivity and pleasure [4]; a space that offers a place for entertainment or social events. Everything is organised and the users do 
not have to engage in preparing the space [16]; landforms such as small hills and fossa.

Culture - a historical place that lets the users feel fascinated by the passing of time [4]. The characteristic itself entails human culture. The significant issues are the historical aspects, how people created value from the environment and how they interconnected the context of culture and nature, where myths and symbols played an important role $[6,16]$. In the case of Tartu, these aspects are ruins.

\subsection{Theories: Tyson's main aspects}

Plants, psychological aspects, senses and visual values were counted as a percentage of greenery.

\subsection{Theories: Searles' elements}

Water/stone, plants, animals and other people are found by answering "Yes/No", while noting the elements' accessibility.

\section{Results}

\subsection{Landscape characteristics (Figures 1 and 2)}

Overall, the author can say that the landscape characteristics can be found in the parks, at least on a low level (1). In that context, the author can divide the landscape characteristics into overall characteristics such as Serene, Wild, Space, Rich in species, and specific characteristics such as Culture, Festivity, Prospect, Refuge. In Tartu, serenity is represented in mid-toned colours in larger greeneries. Wild is mostly found in mid-tones; it is very much present in the perimeter greeneries of the city, based on the historical background. Half of the greeneries are Rich in species thanks to the dendrologic variety of our parks; species-richness is highly represented in the south-west greeneries. Space can be found in the larger areas of the greeneries at the city's perimeter. Festivity is present in certain special places (Toomemägi, ERM and the Botanical Garden) in square-shaped small areas, and represented by mid-toned colours. Culture, Prospect and Refuge can also be found in some special areas.

\subsection{Elements of Searles' theory}

A connection between a person and water/stone was felt in $55 \%$ of the cases. Ülejõe and Vaksali had an advantage thanks to a fountain. Neither of the two could be touched in the Supilinn and Veeriku neighbourhood. Plants growing in the Tartu City greeneries can be found in $99 \%$ of the cases. The missing one percent comes from the front yard of the University of Tartu Library. Animals were present in $64 \%$ of the parks (Veeriku, Vaksali and Supilinn). $78 \%$ of all the greeneries are conversation-friendly. There are no possibilities for conversation in the Ropka neighbourhood. 


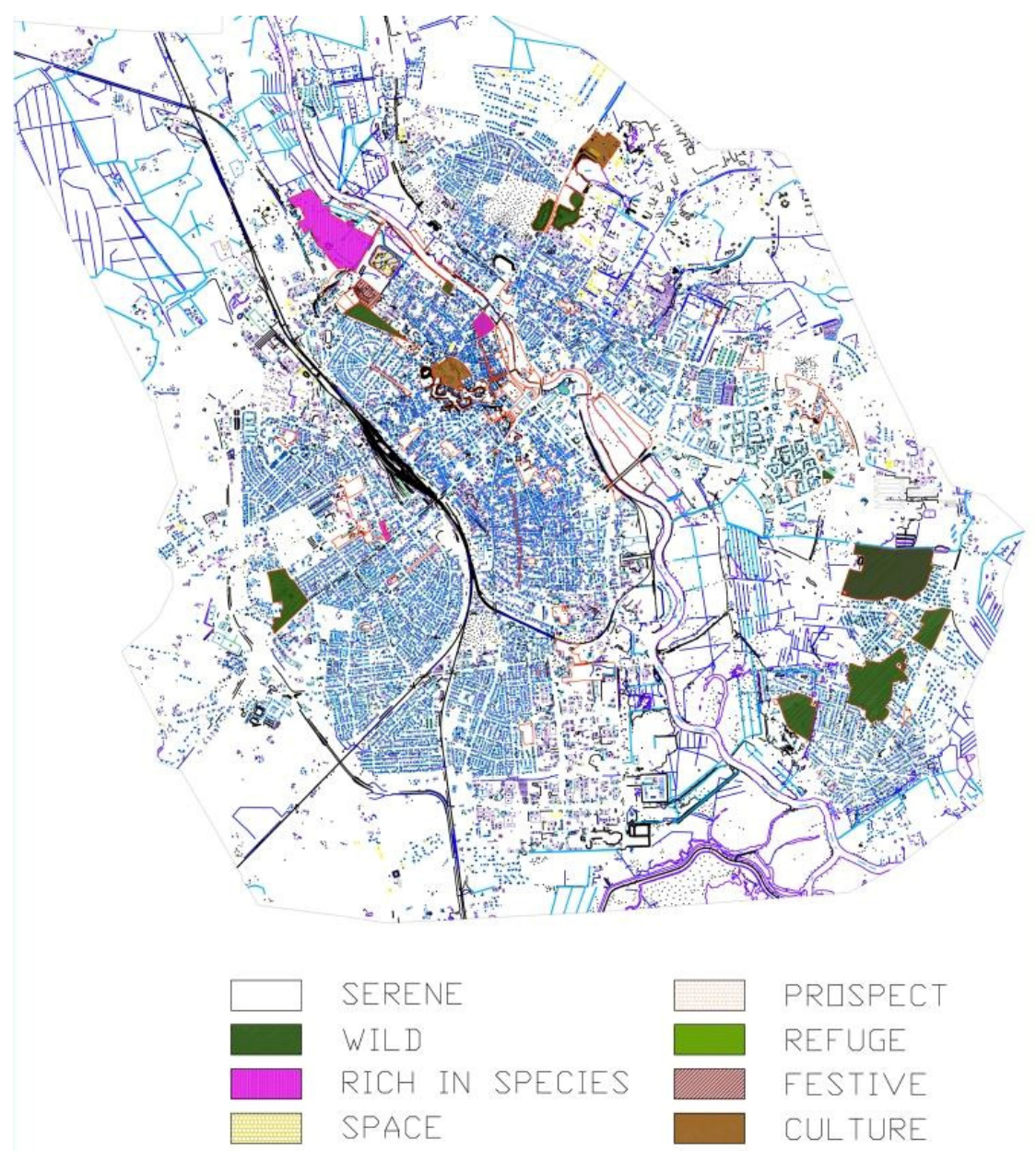

Figure 1: $\quad$ Landscape characteristics in Tartu (strong presence).

\subsection{Main aspects (see Tables 1 and 2, Figure 3)}

The author can statistically prove that design is strongly correlated with user influence through the senses $(\mathrm{r}=0.501, \mathrm{p}<0.01)$. Senses/peace and openness are correlated as follows: $\mathrm{r}=0.412, \mathrm{p}<0.01$. The main aspects provide a variety of senses and different types of visual experiences - mostly various constructed views in case of Tartu. The characteristic serenity is in correlation 
with peace/openness $(\mathrm{r}=0.459, \mathrm{p}<0.01)$, with senses $(\mathrm{r}=0.486, \mathrm{p}<0.01)$ and with visuals $(\mathrm{r}=0.412, \mathrm{p}<0.01)$. The characteristic wilderness correlates with trees/plants $(\mathrm{r}=0.423, \mathrm{p}<0.01)$. The characteristic prospect is connected with visuals $(\mathrm{r}=0.431, \mathrm{p}<0.01)$.

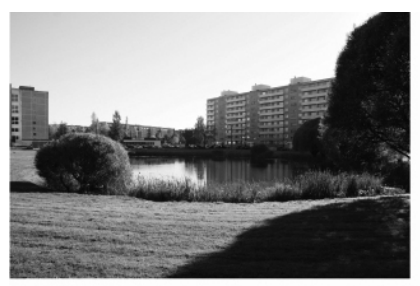

SERENE

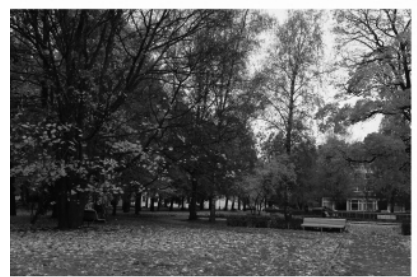

RICH IN SPECIES

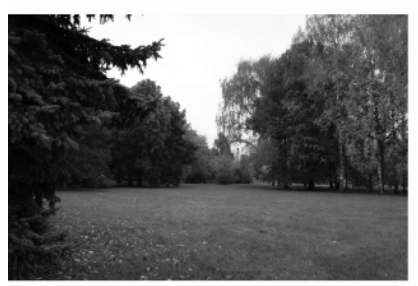

PROSPECT

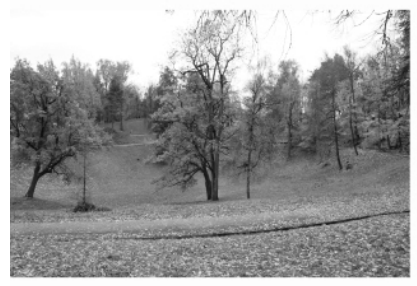

FESTIVE

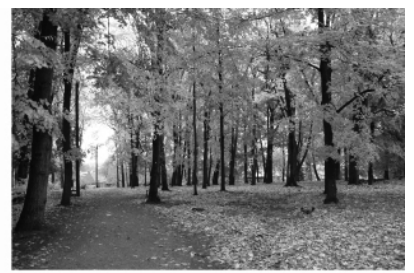

WILD

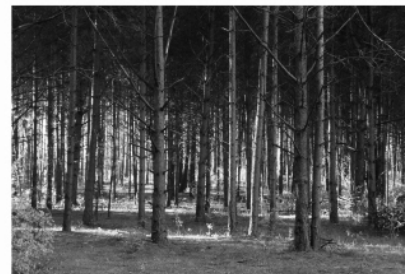

SPACE

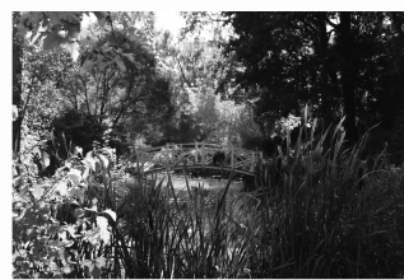

REFUGE

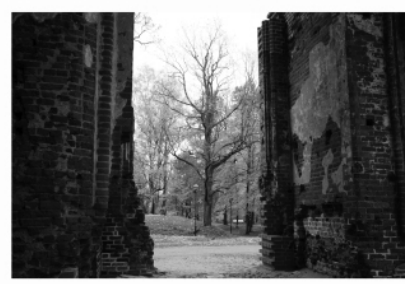

CULTURE

Figure 2: $\quad$ Photos of the landscape characteristics in Tartu parks. 


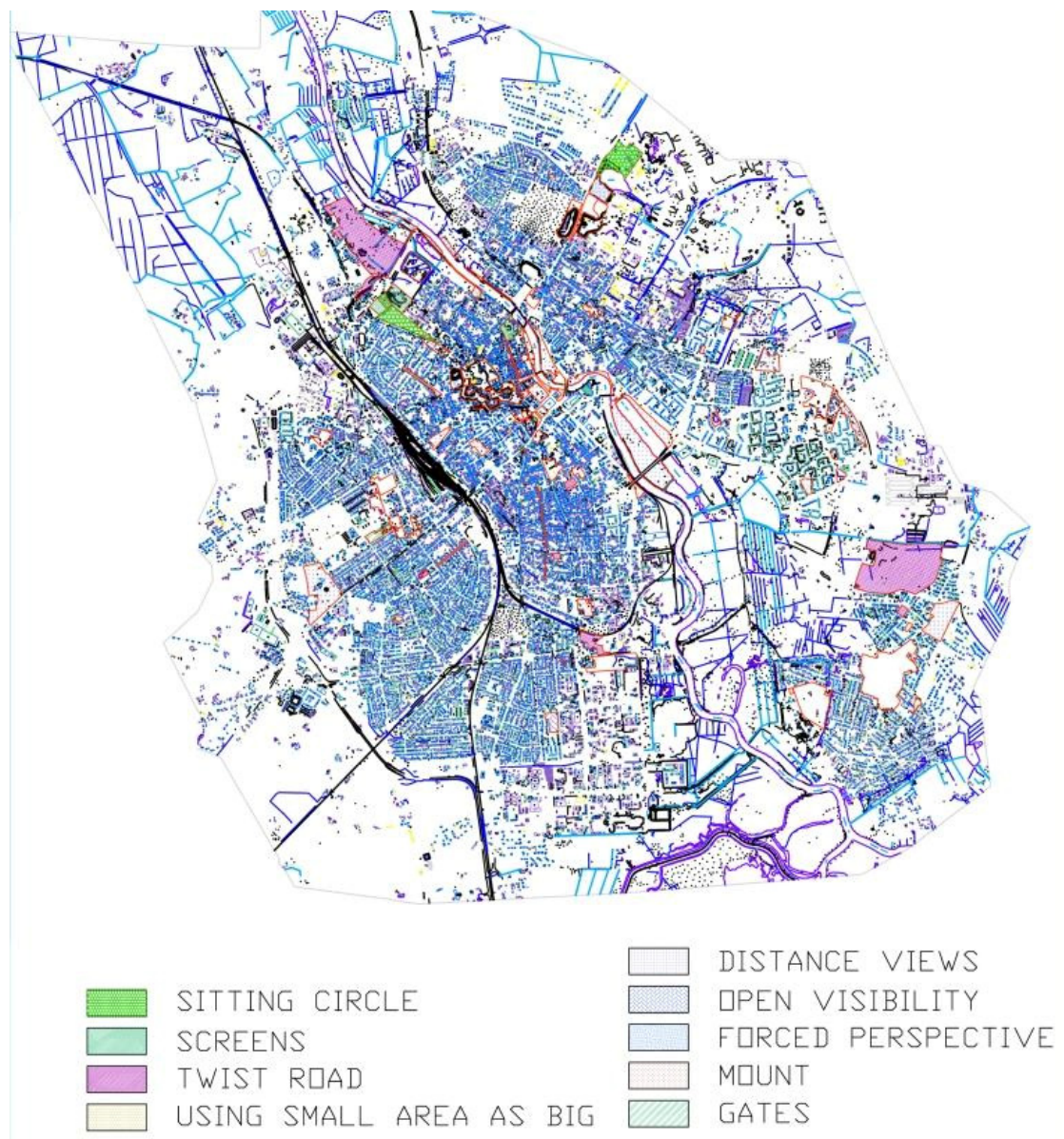

Figure 3: CAD MAP Tyson_visual aspects (different types of views).

Table 1: $\quad$ Main aspects to influence user in landscape through design $\mathrm{N}=92$.

\begin{tabular}{|l|l|l|l|l|}
\hline & Trees/plants & Peace/wideness & Senses & Visuals \\
\hline Trees/plants & 1 & & & \\
\hline Peace/wideness & $-0,017$ & 1 & & \\
\hline & 0,873 & & & \\
\hline Senses &, $238^{*}$ &, $412^{* *}$ & 1 & \\
\hline & 0,022 & 0 & & \\
\hline Visuals &, $231^{*}$ &, $373^{* *}$ &, $501^{* *}$ & 1 \\
\hline & 0,027 & 0 & 0 & \\
\hline
\end{tabular}


Table 2: $\quad$ Landscape characteristic versus Main aspects $\mathrm{N}=92$.

\begin{tabular}{|c|c|c|c|c|}
\hline \multirow{5}{*}{ Serene } & $\begin{array}{c}\text { Trees } \\
\text { /plants }\end{array}$ & $\begin{array}{c}\text { Peace } \\
\text { /wideness }\end{array}$ & Senses & Visuals \\
\cline { 2 - 5 } Wild &, $389^{* *}$ &, $459^{* *}$ &, $486^{* *}$ &, $412^{* *}$ \\
& 0 & 0 & 0 & 0 \\
Rich in Species &, $423^{* *}$ & 0,124 & 0,148 & $-0,057$ \\
& 0 & 0,238 & 0,158 & 0,589 \\
Space &, $294^{* *}$ & 0,141 & 0,111 & 0,167 \\
& 0,004 & 0,179 & 0,292 & 0,111 \\
Prospect &, $397^{* *}$ & 0,196 & 0,079 &, $301^{* *}$ \\
& 0 & 0,061 & 0,452 & 0,004 \\
Refuge & 0,145 &, $227^{*}$ & 0,173 &, $431^{* *}$ \\
& 0,168 & 0,029 & 0,098 & 0 \\
Festive &, $218^{*}$ &, $220^{*}$ &, $296^{* *}$ &, $244^{*}$ \\
& 0,037 & 0,035 & 0,004 & 0,019 \\
Culture & $-0,2$ & 0,09 & 0,1 & 0,103 \\
& 0,056 & 0,394 & 0,341 & 0,329 \\
& $-0,056$ & 0,06 & 0,143 &, $342^{* *}$ \\
\hline \multirow{2}{*}{} & 0,593 & 0,571 & 0,173 & 0,001 \\
\hline
\end{tabular}

\section{Discussion}

\subsection{Landscape characteristics}

Literature on forest aesthetics clearly indicates that observers prefer park-like settings [17] as city residents get greater benefit from viewing the natural city scenery [12], which is also confirmed by visual aspects. Health promotion is the most sensitive to disruption, because these dimensions - Serene, Space and Rich in species - require large areas of land [4]. This study can confirm that Serene can be found in large green areas [5]. The author's earlier works confirm the same results while looking at the environment through landscape characteristics, considering the presence of the personal/impersonal feeling [18]; Bell calls these distance senses [14]. The overlapping of descriptions is a problem associated with landscape characteristics [19]. There can also easily be several landscape characteristics in one place - the most influential is the one marked in bold tones. Looking at the landscape, it is important to find eight characteristics, which do not overlap. Based on characteristics and theories, there can be many layers in the same place (design themes or topics). It is also easier to work with natural material in the city - there are no changeable factors, the user can experience many different aspects. If such information is gathered directly from the landscape with exact descriptions, it is also easier to find the characteristics and the results will be clearer - an average person (without any disabilities) can get the same results even after decades (landscape characteristics are developed based on the park environment). This paper confirms that the characteristic of Prospect and visuals are related. As landscape characteristics function in one cultural room, this study confirms that the wilderness characteristic in Estonia is connected with trees and plants. Considering studies carried out in Sweden, it is 
comparable to the ancient wilderness found in the forest. Comparing the existence of the serenity characteristic to the healing gardens of England, then it can be said that serenity is prominent in Estonia [18]. While the information is related to greeneries that are similar, then the statistical results are not so highly correlated in case of parks due to the level of the work method used. Compared to papers on healing garden characteristics [5], there are stronger correlations in healing gardens. Serenity is connected with all the expected visual dimensions. In order to have more characteristics in a park, smaller gardens could be incorporated into larger ones. The authors of landscape characteristics have revealed that serenity, spaciousness and culture appeal to many people; vulnerable people often see commonness and stressed people see festivity. Based on the existence of characteristics in Tartu, and the other articles published, the author showed that the characteristics wilderness and serenity, refuge and space, culture and festivity exist together in Tartu greeneries.

\subsection{Main aspects and elements}

All the visual aspects were correlated to serenity. Considering greenery, it can be said that the descriptions of characteristics do not focus on the absence of things, but on all three visual main aspects.

\subsection{Design}

The design and the contents of the outdoor environment seem to be of importance for the recovery of a stressed individual visiting the environment [13]. These findings suggest that when designing gardens and selecting garden features, attention should be paid to person-environment transactions in addition to person-person transactions [20]. Landscape architects require more than knowledge of the types of preferred settings; the designed settings must also support the behaviours they were intended for if they are to be successful [21]. The design-to-senses correlation was a surprise, because few landscape accessories in design actually have another dimension.

\section{Conclusion}

Landscape characteristics are developed further to PSDs and the author found that there are also other ways such as landscaping, the interaction between the user and other dimensions. They were developed on the basis of city parks and are excellent for evaluating parks. This paper added some visual dimensions like Searles' elements and the main aspects that influence the user most in the landscape, and interpreted them from the point of view of a landscape designer. Some of the results that came up were very useful, such as the finding that the design and the senses are connected in Tartu. Judging from the results, the author can say that Tartu is a healing city based on greeneries. It is important to keep all eight landscape characteristics in the landscape arena. It's important to know all the information there is to know about the landscapes where people are sent to heal, while talking about gardens and stressed people who use public parks. 


\section{Acknowledgements}

Digital CAD-MAP was received from Tartu City Government through a bilateral agreement between them and Estonian University of Life Sciences.

\section{References}

[1] Kudu E, Toome pargi ajalugu, 1971.

[2] TARTU LINNA TERVISEPROFIIL 2008, Tartu LV, 2010.

[3] Aleksandrovaite, L. Tartu elanike juurdepääs avalikele haljasaladele ning avalike haljasalade kvaliteedi analüüs. EPMÜ KKI. Tartu, 2004.

[4] Berggren-Bärring A-M and Grahn P, Importance of the single park area on experienced characteristics. Ecological aspects of Green Areas in Urban Environments. IFPRA World Congress Proceeding, 110. Antwerp, Flanders, Belgium, 1995.

[5] Stigsdotter, U. K., Grahn, P., Stressed individuals' preferences for activities and environmental characteristics in green spaces. Urban Forestry \& Urban Greening, 10(4), pp. 295-304, 2011.

[6] Stigsdotter, U. A., Grahn, P. What makes a garden healing garden? Journal of Therapeutic Horticulture, 13, pp. 60-69, 2002.

[7] Berggren-Bärring, A-M. \& Grahn, P. Grönstrukturens betydelse för användningen: En jämförande studie av hur människor i barnstugor, skolor, föreningar, vårdinstitutioner $\mathrm{m} \mathrm{fl}$ organisationer utnyttjar tre städers parkutbud. Landskapsplanering Rapport 95:3, Alnarp. 1995.

[8] Tyson M, The Healing Landscape: Therapeutic Outdoor Environments, McGraw-Hill, 1998.

[9] Ulrich, R, Effects of gardens on health outcomes: Theory and research. Healing Gardens: Therapeutic Benefits and Design Recommendations. New York: John Wiley, pp. 27-86, 1999.

[10] Driver, B. L., Dustin, D., Baltic, T., Elsner, G. and Peterson, G. L. Nature and the Human Spirit: Toward an Expanded Land Management Ethic. Venture Publishing, Inc., State College, PA., 1996.

[11] Kaplan, R., The role of nature in the urban context, Behavior and the Natural Environment. Plenum, New York, NY, pp. 127-162, 1983.

[12] Ulrich, R, Human responses to vegetation and landscapes, Landscape and Urban Planning, 13, pp. 29-44, 1986.

[13] Grahn P. and Stigsdotter U. Landscape planning and stress, Urban Forestry and Urban Greening, 2003.

[14] Bell S, Landscape: Pattern Perception and Process, E \& F N Spon, London, 1999.

[15] Searles HF, The Nonhuman Environment in Norman Development and in Schizophrenia. International Universities Press, New York, 1960.

[16] Grahn, P., Stigsdotter, U. K., The relation between perceived sensory dimensions of urban green space and stress restoration. Landscape and Urban Planning, 94, pp. 264-275, 2010. 
[17] Patey and Evans, Identification of scenically preferred forest landscapes, Berkeley, CA. pp. 532-53, 1979.

[18] Maikov, K; Bell, S; Sepp, K, A comparison of the evaluation of room characteristics of healing gardens. Design and Nature IV, Wessex Institute of Technology Press, pp. 223-232, 2008.

[19] Skärbäck, E, Landscape planning to promote well-being: studies and examples from Sweden. Environmental Practice, 9(3): pp. 206-217, 2007.

[20] Sherman A., Varni W, Ulrich R, Malcarne L, Post-occupancy evaluation of healing gardens in a pediatric cancer center, Landscape and Urban Planning, 2005.

[21] Barnhart SK, Perkins NH, Fitzsimonds, Behaviour and outdoor setting preferences at a psychiatric hospital, Landscape and Urban Planning 42, pp. 147-156, 1998. 